\title{
EPINEPHRINE METABOLITES AND PIGMENTATION IN THE CENTRAL NERVOUS SYSTEM IN A CASE OF PHENYLPYRUVIC OLIGOPHRENIA
}

\author{
BY \\ J. H. FELLMAN* \\ From the Division of Neurology, University of Oregon Medical School, Portland, U.S.A.
}

The biochemical lesion associated with mental deficiency in phenylpyruvic oligophrenia is a failure of an enzyme system in these individuals to hydroxylate phenylalanine to tyrosine (Jervis, 1953). The biochemical ramifications of this single genetic loss are vast, but as yet no direct evidence has been forthcoming which specifically relates the appearance of the biochemical abnormality to the mental deficiency. Phenylalanine (Jervis, Block, Billing, and Kunze, 1940) and phenyllactic acid (Goldstein, personal communication) have been shown to accumulate in the blood and other tissue fluids and a variety of aberrant aromatic metabolites have been demonstrated in the urine (Woolf, 1951; Armstrong and Robinson, 1954; Boscott and Bickel, 1953). The light hair and fair skin which has been noted in a large majority of these patients suggest that melanocyte tyrosinase is competitively inhibited by the phenylalanine and the related abnormal metabolites. This suggestion gains support from recent publications which show that these patients maintained on synthetic diets deficient in phenylalanine manifest considerable pigmentation of the hair (Armstrong and Tyler, 1955). Further support for this mechanism appear from studies in vitro which demonstrated competitive inhibition of plant (Dancis and Balis, 1955) and mammalian (Miyamoto and Fitzpatrick, 1957) tyrosinase by phenylalanine and its associated abnormal aromatic metabolites.

The recent finding that patients afflicted with phenylpyruvic oligophrenia have low epinephrine plasma levels (Weil-Malherbe, 1955) suggests a further interference with enzyme systems concerned with aromatic amino-acid metabolism. This observation led us to examine the effects of phenylalanine and the associated aromatic acids on the tyrosinase activity of human phaeochromacytoma homogenates and on the D.O.P.A. decarboxylase activity obtained from beef adrenal medulla. We found tyrosinase activity to be inhibited by phenylalanine

*Supported by United States Public Health Grant H 2676.
(Fellman, unpublished observations), whereas D.O.P.A. decarboxylase activity was not affected by phenylalanine, but was inhibited by phenylpyruvic and phenyllactic acids (Fellman, 1956).

We have recently had the opportunity of examining post-mortem tissue of a 14-year-old patient who died with phenylpyruvic oligophrenia $\dagger$, and it is the results of these pursuits which shall be given below. Two areas of aromatic amino-acid metabolism were investigated. The aromatic amino-acids which give rise to epinephrine and the pigmentation of certairp cells of the central nervous system, the substantia nigra and the locus coeruleus.

\section{Methods}

Epinephrine Intermediates.-The glands were obtaineed two hours after death, quick frozen, and maintained a $-20^{\circ}$ until used. The gland was ground in a mortas with acid-washed sand and $50 \mathrm{ml}$. of $0.01 \mathrm{~N} \mathrm{HCl}$. The homogenate was centrifuged at $800 \mathrm{x} / \mathrm{g}$. for 20 minutes to remove debris and sand and recentrifuged at $25,000 \mathrm{x} / \mathrm{g}$. for half an hour to remove finer particles. The supernatant was used for the fluorometric (Lund, 1949) and biological (Burn, Finney, and Goodwin, 1950) estimation of epinephrine and norepinephrine. Eighteen millilitres of the supernatant were lyophilized and taken up in $0.9 \mathrm{ml}$. of $0.001 \mathrm{~N} \mathrm{HCl}$ and used for identification of amino-acids and aromatic intermediates in the gland by paper chromatography. For most chromatographic analysis, Whatman one part, butanol four parts, acetic acid one part, water five was used; however, occasionally butanol 600 parts, formic 50 parts, water 50 parts was used as a solvent to establish homogeneity of the isolated spots. The components of the extract were isolated by paper chromatography. A band of gland extract was permitted to separate in butanol, acetic acid, and water; one edge of the chromatogram was cut, developed with ninhydrin, and, with this as a guide, fractions were obtained by cutting crossways to correspond with the developed strip. These fractions were eluted with $15 \mathrm{ml}$. of $0.001 \mathrm{~N} \mathrm{HCl}$, lyophilized, and rechromatogrammed. In the case of tyrosine and methionine, admixture experiments were run with the corresponding radioactive

†The pathological report is to be published elsewhere. 
amino-acids to establish identity by the coextensivity of radioactivity and colour. Carbon ${ }^{14}$ radioactivity was determined by scanning with an end window counter.

Histochemical. - The brain was removed approximately two hours after death and fixed in $10 \%$ formalin. Sections were cut from paraffin blocks $15 \mu$ thick and stained either with toluidine blue or with the protargol-silver method of Stotler (1951) to reveal argentophilic material.

\section{Results}

Adrenal Gland Extracts. - The extract of the gland contained $425 \gamma$ epinephrine/g. gland and $7 \gamma$ norepinephrine/g. gland estimated by a modified fluorometric method of Lund. Normal adult values for the pressor amines are $209 \gamma / \mathrm{g}$. gland adrenaline and $31 / \mathrm{g} . \gamma$ gland noradrenaline (Shepherd and West, 1951). The biological assay employing the rat uterus and rabbit ileum indicated a concentration of $434 \gamma$ epinephrine/g. gland while the concentration of norepinephrine was so small that accurate estimation of this material was difficult with this method. Both pressor amines were detected with a paper chromatographic technique (Table I); however, our experiences indicated that very little norepinephrine was present, corroborating our other methods.

TABLE I

CHROMATOGRAPHIC IDENTIFICATION OF EPINEPHRINE AND NOREPINEPHRINE IN ADRENAL GLAND

\begin{tabular}{l|c|c|c|c}
\hline & Rf(BAW) & Ninhydrin & Diazo Sulph. & $\mathrm{NaIO}_{3}$ \\
\hline Epinephrine & 0.30 & Blue violet & Violet & Pink \\
Unknown No. 5 & $0 \cdot 31$ & Blue violet & Violet & Pink \\
Norepinephrine & $0 \cdot 22$ & Blue violet & Violet & Violet \\
Unknown No. 5 & 0.22 & Blue violet & Violet & Violet \\
\hline
\end{tabular}

The identification of three amino-acids which appear in the gland is given in Table II and Table III.

TABLE II

CHROMATOGRAPHIC IDENTIFICATION OF TYROSINE IN ADRENAL GLAND

\begin{tabular}{|c|c|c|c|c|}
\hline & $\begin{array}{c}\mathbf{R f} \\
(\mathrm{BAW})\end{array}$ & Ninhydrin & $\begin{array}{l}\text { Diazo } \\
\text { Sulph. }\end{array}$ & $\begin{array}{c}\text { Radioactive } \\
\text { Tracer }\end{array}$ \\
\hline Tyrosine & 0.37 & & Orange & Coextensive \\
\hline Unknown & 0.37 & Blue & Orange & $\begin{array}{l}\text { Coextensive } \\
\text { with colour }\end{array}$ \\
\hline
\end{tabular}

TABLE III

CHROMATOGRAPHIC IDENTIFICATION OF METHIONINE AND PHENYLALANINE IN THE ADRENAL GLAND

\begin{tabular}{|c|c|c|c|c|}
\hline & $\underset{(\mathbf{B A W})}{\mathbf{R f}}$ & Ninhydrin & $\begin{array}{l}\text { Diazo } \\
\text { Sulph. }\end{array}$ & $\underset{\text { Tracer }}{\text { Radioactive }}$ \\
\hline Methionine & 0.40 & Red & - & Coextensive \\
\hline $\begin{array}{l}\text { Unknown } \\
\text { No. } 7\end{array}$ & 0.41 & Red & - & $\begin{array}{l}\text { with colour } \\
\text { Coextensive } \\
\text { with colour }\end{array}$ \\
\hline Phenylalanine & 0.55 & Blue violet & Grey & - \\
\hline $\begin{array}{l}\text { Unknown } \\
\text { No. } 9\end{array}$ & 0.56 & Blue violet & $\begin{array}{l}\text { (fluorescent) } \\
\text { Grey } \\
\text { (fluorescent) }\end{array}$ & - \\
\hline
\end{tabular}
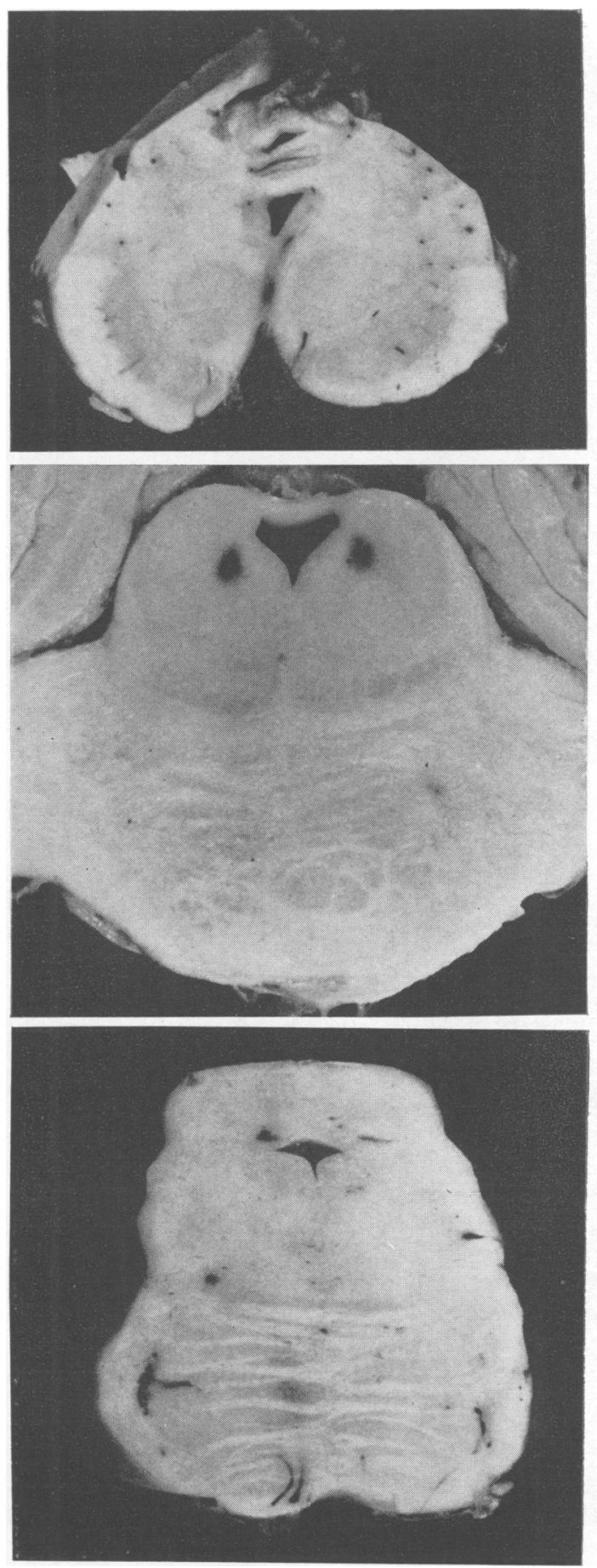

FIG. 1.-Cross section through the midbrain (upper photograph) of the case discussed, showing unpigmented substantia nigra.

Cross section through fourth ventricle (middle) of the case discussed, showing unpigmented locus coeruleus.

Cross section through fourth ventricle (lower) of norma individual showing pigmented locus coeruleus. 
Their concentration in the gland was estimated from the intensity of ninhydrin colour and was in the order of $150 \gamma$ tyrosine/g. gland, $900 \gamma$ phenylalanine/ g. gland, and $200 \gamma$ methionine/g. gland. It should be mentioned that the concentration of phenylalanine determined in the blood of this patient one month before death by the method of KapellerAdler (1932) was $53 \mathrm{mg} . \%$.

Pigmentation of Cells of Substantia Nigra and Locus Coeruleus.- Hypopigmentation of the substantia nigra and locus coeruleus was evident in gross sections (Fig. 1). When sectioned and stained with toluidine blue these areas revealed an absence of pigment granules (Fig. 2, B, D), however, Nissl's bodies were clearly evident. Sections treated with the protargol-silver procedure revealed small intracellular argentophillic granules which will be discussed below (Fig. 2, $A, C$ ). Cells from a normal individual stained with both toluidine blue (Fig. 2, $F$ ) and protargol-silver (Fig. 2, E) are shown for purposes of comparison.

\section{Discussion}

The adrenal gland of man and other animals normally contains free phenylalanine (Fellman, unpublished observations). Tyrosine and methionine do not appear to be present except in certain disease states. We have detected these amino-acids in the case discussed as well as in two other pathological states, one involving a child of 4 who died of a neuroblastoma primary to the adrenal. At necropsy massive secondary invasion of the liver and other tissue was observed. The second case was a 50-yearold adult who died in hepatic coma with cirrhosis of the liver. In both conditions free phenylalanine, tyrosine, and methionine could be detected in the adrenal gland. However, the amino-acids could also be detected in blood and in other tissue, probably as a result of liver failure and general metabolic derangement.

The accumulation of tyrosine may result from the inhibition of adrenal tyrosinase by the appearance of abnormally high amounts of phenylalanine in phenylpyruvic oligophrenia. A similar mechanism may account for the appearance of this amino-acid in the adrenal glands of the other conditions mentioned. Common to all three disease states is the appearance of free circulating phenylalanine. The appearance of methionine in these extracts may relate to its methylating functions in this gland. The high ratio of epinephrine to norepinephrine indicates, however, that methylation of the latter to the former does take place.

The examination of pigment formation in the cells of the substantia nigra and locus coeruleus clearly indicates an absence of the melanin material. $*$ \& The substantia nigra is an area of the midbrain part of the extrapyramidal system, the cells of which in man, primates, and certain other mammals nor- $\bar{c}$ mally contain a melanin pigment (Brown, 1943). T) The functional significance of the locus coeruleus is unknown. Like the substantia nigra, pigment formation begins at the age of 4 years and continues steadily throughout life (Adler, 1942). Other investigators report pigment granules in the locus coeruleus at all ages, even in the seventh month of $\overrightarrow{0}$ foetal life while in the cells of the substantia nigra 듬 pigment granules have not been observed until the $\frac{\bar{D}}{\bar{D}}$ eighteenth month of life (Foley and Baxter, 1956). $ه$ Little is known about the mechanism of melanin formation in these cells. The formation of melanin ${ }^{\circ}$ in the melanocytes of the skin and hair matrix has $\vec{\circ}$ for some time, however, been understood as resulting $\vec{\overrightarrow{ }}$ from the oxidative polymerization of tyrosine by $\stackrel{\omega}{\omega}$ the tyrosinase in these cells (Kukita and Fitzpatrick, 1955). These series of enzymatic and non-enzymatic alterations of tyrosine produce an insoluble black- i brown pigment which is believed to be bound by primary chemical bonds to a protein of the ceff (Serra, 1946). From what has already been stated in this paper about the derangement of skin and ha: pigmentation in phenylpyruvic oligophrenia, do ouf 7 observations of hypopigmentation in the cells of $\mathbb{P}$ the central nervous system in this disease indicat that tyrosine oxidation is responsible for melani formation in the central nervous system ? One. cannot assume that this necessarily follows.

First, while skin and hair matrix tyrosinase is lacking in human albinos (Kukita and Fitzpatrick, 1955), normal pigmentation of the substantia nigra is observed in this genetic anomaly (Foley and Baxter, 1956). Since the embryological origin of $\stackrel{2}{D}$ both the skin melanocytes and the central nervous $\underset{\square}{\square}$ system is the neural crest, we might expect that if the $\overrightarrow{\overrightarrow{0}}$ same enzyme were involved a genetic loss would be 3 reflected to wherever this enzyme occurred.

Secondly, the failure to demonstrate D.O.P.A. oxidase activity in the substantia nigra (Foley and Baxter, 1956) and the demonstration of this enzyme $\frac{7}{0}$ in melanocytes further suggests that tyrosine oxida- $:$ tion to melanin is not the mechanism for pigment formation in the central nervous system.

What, then, is the substrate for the elaboration of pigment in the central nervous system ? An attrac- o tive possibility is that this pigment represents a pressor amine melanin, that is, a melanin formed from the oxidative polymerization of either epine-

\footnotetext{
*In a pathological report of a case of phenylpyruvic oligophrenia, $N$ brief mention was made of hypopigmentation, namely, "The nerve $\bigcirc$ cells of the substantia nigra appear to contain rather small amounts $\omega$ of pigment" (Corsellis, 1953).
} 

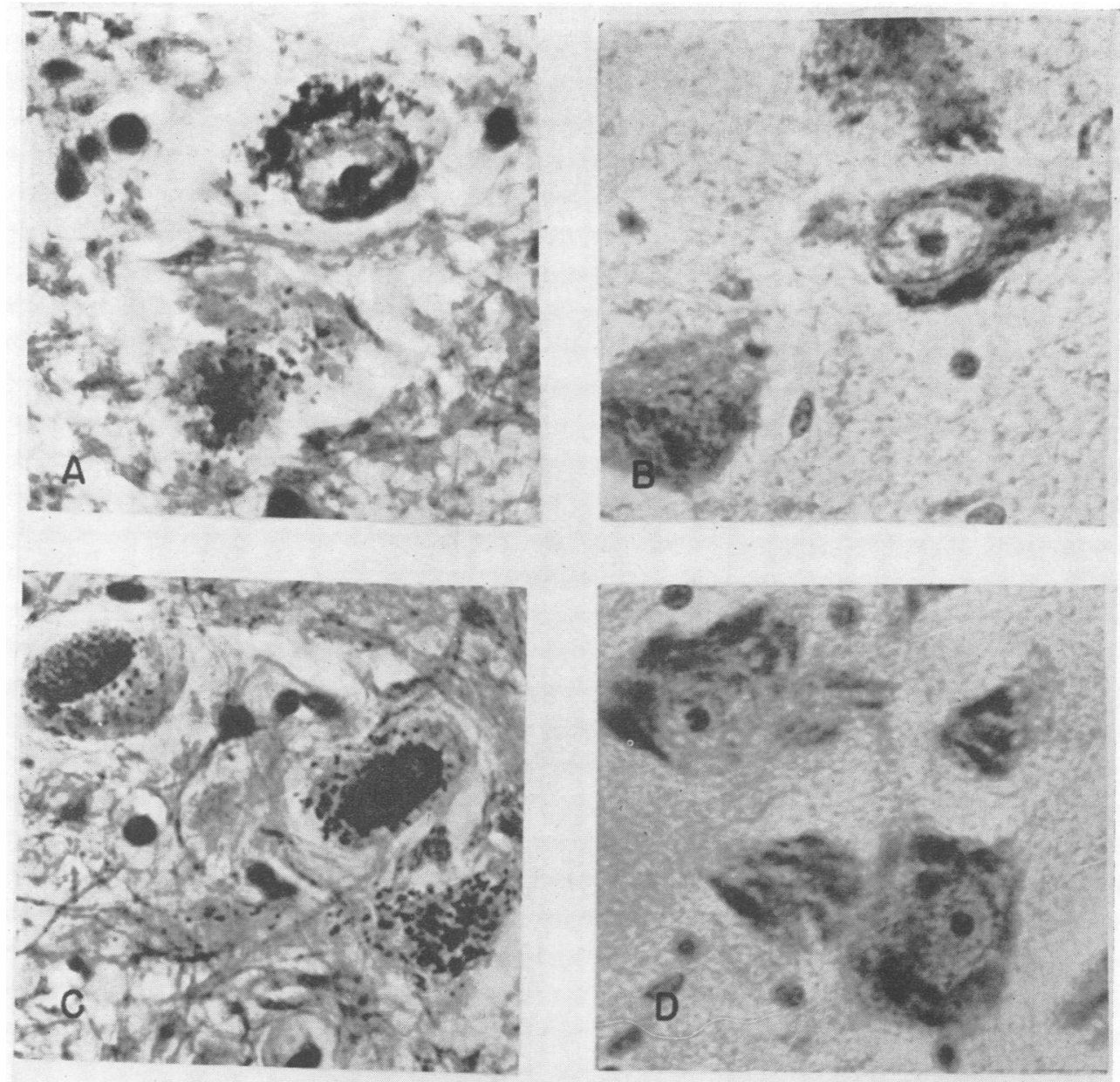

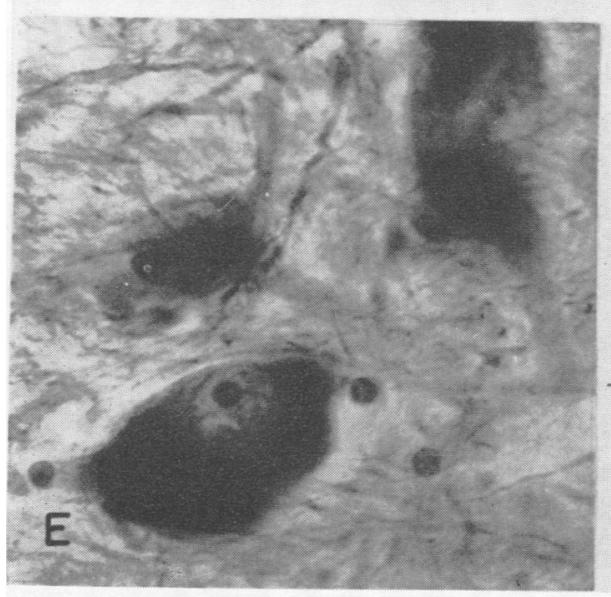

Fig. 2.-A. Cells of the locus coeruleus from case discussed stained with protargol-silver.

$C$. Cells of the substantia nigra from case discussed stained with protargol-silver.

$E$. Cells of the substantia nigra from normal individual stained with protargol-silver.

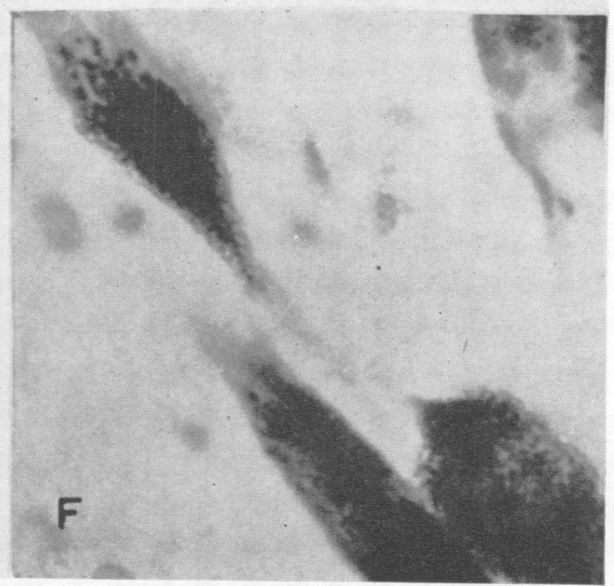

$B$. Cells of the locus coeruleus from case discussed stained with toluidine blue.

$D$. Cells of the substantia nigra from case discussed stained with toluidine blue.

$F$. Cells of the substantia nigra from normal individual stained with toluidine blue. 
phrine or norepinephrine. We have some support for such a view. This would represent a useful mechanism for elimination of the pressor amine, a detoxification in situ as it were, and would account for the accumulation of pigment over the life span of the animal. The argentophillic granules may represent precursors of pigment formation in the substantia nigra. We have observed this argentophillic material in young, unpigmented cat and rat substantia nigra cells. These argentophillic granules are not unlike those observed in adrenal medulla and other chromaffin sites.

We may mention in passing that the accepted function for pigmentation in the skin relates to its ability to absorb harmful wavelengths of light. Surely this is not its function in the central nervous system.

The evidence presented in this paper points to two additional areas of aberrant aromatic aminoacid metabolism in phenylpyruvic oligophrenia: (1) Epinephrine biosynthesis in adrenal tissue, and (2) pigmentation of the cells of the central nervous system. With these observations we implicate alteration of metabolism in the central nervous system which probably results from the initial biochemical lesion in this disease. Obtaining from this also is the attitude that the cause of the mental deficiency associated with this genetic deficiency probably stems not from an intoxication by phenylalanine per se, but rather a distortion of a mutually interdependent system of aromatic metabolism leading to bizarre metabolic products and inhibition of vital biochemical pathways.

\section{Summary}

Two sites of aromatic amino-acid metabolism were examined in post-mortem material from an individual who died with phenylpyruvic oligophreniathe adrenal gland and pigment cells in the central nervous system.

The adrenal extracts contained epinephrine, norepinephrine, tyrosine, methionine, and phenylalanine. Extracts from normal adrenal glands contain epinephrine, norepinephrine, and phenylalanine.

The cells of the substantia nigra and locus coeruleus did not contain pigment.

The implications of these observations to the disease and to pigment formation are discussed.

The author wishes to express his sincere thanks to Dr. Louis Lino, Miss Mary K. Devlin, Dr. Philip Suver, and Dr. William Stotler for their assistance and participation in this work.

\section{REFERENCES}

Adler, A. (1942). J. comp. Neurol., 76, 501.

Armstrong, M. D., and Robinson, K. S. (1954). Arch. Biochem. Biophys., 52, 287.

, and Tyler, F. H. (1955). J. clin. Invest., 34, 565.

Boscott, R. J., and Bickel, H. (1953). Scand. J. Lab. clin. Invest. $5,380$.

Brown, J. O. (1943). J. comp. Neurol., 79, 393.

Burn, J. H., Finney, D. J., and Goodwin, L. G. (1950). Biologica Standardization, 2nd ed., p. 222. Oxford University Press London.

Corsellis, J. A. N. (1953). J. Neurol. Neurosurg. Psychiat., 16, 139.

Dancis, J., and Balis, M. E. (1955). Pediatrics, 15, 63.

Fellman, J. H. (1956). Proc. Soc. exp. Biol. (N.Y.), 93, 413.

Foley, J. M., and Baxter, D. (1956). J. Neuropath., 15, 219.

Jervis, G. A. (1953). Proc. Soc. exp. Biol. (N.Y.), 82, 514 Block, R. J., Billing, D., and Kunze, E. (1940). J. biol. Chem. 134, 105.

Kapeller-Adler, R. (1932). Biochem. Z., 252, 185

Kukita, A., and Fitzpatrick, T. N. (1955). Science, 121, 893.

Lund, A. (1949). Acta pharmacol. (Kbh.), 5, 231.

Miyamoto, M., and Fitzpatrick, T. (1957). Nature (Lond.), 179, 199.

Shepherd, D. M., and West, G. B. (1951). Brit. J. Pharmacol., 6, 665

Stotler, W. A. (1951). Anat. Rec., 109, 385.

Serra, J. A. (1946). Nature, (Lond.), 157, 771.

Weil-Malherbe, H. (1955). J. ment. Sci., 101, 733.

Woolf, L. I. (1951). Biochem. J., 49, ix. 